\title{
Direct Preparation of the Nanocrystalline MnZn Ferrites by Using Oxalate as Precipitant
}

\author{
Fei Hua',2, Cuicui Yin'1, Huanque Zhang33, Qiangqiang Suo ${ }^{3}$, Xin Wang1, Huifen Peng1 \\ ${ }^{1}$ School of Materials Science \& Engineering, Hebei University of Technology, Tianjin, China \\ ${ }^{2}$ Department of Fire Protection Engineering, Chinese People's Armed Police Force Academy, Langfang, China \\ ${ }^{3}$ School of Chemical Engineering, Hebei University of Technology, Tianjin, China \\ Email: hpeng226@163.com
}

Received 28 September 2015; accepted 10 December 2015; published 17 December 2015

\begin{abstract}
Oxalate was generally used as a precipitant for synthesis of MnZn ferrites during the co-precipitation process. However, the MnZn ferrite couldn't be directly obtained and a calcination process was needed. In this research, we reported a direct preparation of the $\mathrm{MnZn}$ ferrite nanoparticles by using co-precipitation method, together with refluxing process. XRD measurements proved that crystallite size of the obtained samples increased with an increase in pH value of the co-precipitation solution, and that the crystallite size of about $25 \mathrm{~nm}$ was obtained for the sample at a pH of 13. This sample showed the maximum $M_{s}$ of $58.6 \mathrm{emu} / \mathrm{g}$, which was about one times larger than that of 12 (pH value). Calcination to the obtained samples result in an enlargement in their crystal size and an improvement in their magnetic properties with an increase in temperatures. The samples calcinated in $\mathrm{CO}_{2}+\mathrm{H}_{2}$ atmosphere presented good stability, and the maximum $\mathrm{M}_{\mathrm{s}}$ value of $188.2 \mathrm{emu} / \mathrm{g}$ was obtained for the $1100^{\circ} \mathrm{C}$-heated sample. Unfortunately, precipitation of some $\mathrm{Fe}_{2} \mathrm{O}_{3}$ at $800^{\circ} \mathrm{C}$ suggested poor stability of the nanocrystalline MnZn ferrite in $\mathrm{N}_{2}$ atmosphere.
\end{abstract}

\section{Keywords}

Magnetic Material, MnZn Ferrite, Co-Precipitation Process, Nanocrystalline Material

\section{Introduction}

MnZn ferrite is one of the most important soft ferrites, which present high magnetic permeability, high saturation magnetization, high resistivity, low coercivity, low power losses and so on [1]. It is widely used in many fields, such as deflection yoke rings, computer memory chips, magnetic recording heads, microwave devices, transducers, transformers and so on [2]. Additionally, nano-sized MnZn ferrite is a good candidate for biomedical purposes, including magnetically guided drug delivery and magnetic resonance image [3], because of its high magnetic moment, good chemical stability and reactive surfaces when attaching to biological molecules [4].

Ferrite is usually synthesized by the conventional ceramic technique, where high temperature is needed in order for enough solid-state reactions between raw materials, large and inhomogeneous particles, together with 
some impurities, greatly restrict magnetic properties of the products [5]-[7. Therefore, wet chemical synthesis like co-precipitation [8]-[10], sol-gel [11] [12], hydrothermal method [13], and micro-emulsion process [14] [15] is expected for the production of ferrites with excellent magnetic properties. Among these methods, co-precipitation process is often used to the preparation of the homogeneous ferrite nanoparticles [4]. During this process, oxalate is generally used as a precipitant to prepare the ferrite powder. Angerman et al. [16] reported that $\beta$-oxalate with orthorhombic structure was formed when precipitating at room temperature, and that monoclinic $\alpha$-oxalate was obtained at $90^{\circ} \mathrm{C}$. Those oxalates could be completely transformed to ferrite when decomposition at $650^{\circ} \mathrm{C}$ [17]. On the other hand, Fritsch et al. [18] found that Mn-riched ferrite $\left(\mathrm{Fe}_{3-\mathrm{x}} \mathrm{Mn}_{\mathrm{x} \square 3 \delta / 4} \mathrm{O}_{4+\delta}\right)$ with $\mathrm{x}>1.5$ presented complex structures like cubic, tetragonal or a mixture of them. This phenomenon should be attributed to the lack of miscibility at low temperature in the $\mathrm{Fe}_{3} \mathrm{O}_{4}-\mathrm{Mn}_{3} \mathrm{O}_{4}$ system. In this paper, nanocrystaline MnZn ferrite was directly synthesized at room temperature by using the co-precipitation method, followed by a refluxing process. We investigated structures of the products and their phase transitions during heating under different atmosphere.

\section{Experimental}

\subsection{Sample Preparation}

Reagent-grade $\mathrm{FeCl}_{3} \cdot 6 \mathrm{H}_{2} \mathrm{O}$ (Bodi Chemical, Tianjin, 99\%), $\mathrm{ZnSO}_{4} \cdot 7 \mathrm{H}_{2} \mathrm{O}$ (Bodi Chemical, Tianjin, 99.5\%), $\mathrm{MnSO}_{4} \cdot \mathrm{H}_{2} \mathrm{O}$ (Bodi Chemical, Tianjin, 99\%) were used as starting materials. Reagent-grade $\left(\mathrm{NH}_{4}\right)_{2} \mathrm{C}_{2} \mathrm{O}_{4} \cdot \mathrm{H}_{2} \mathrm{O}$ (Fengchen Chemical, Tianjin, 99.8\%) and $\mathrm{NaOH}$ (Bodi Chemical, Tianjin, 99\%) were used as co-precipitants, they were dissolved into de-ionized water at a concentration of $0.2 \mathrm{~mol} / \mathrm{L}$ and $6 \mathrm{~mol} / \mathrm{L}$, respectively. $\mathrm{NH}_{3} \cdot \mathrm{H}_{2} \mathrm{O}$ (Fengchen Chemical, Tianjin, 25\%) was used during precipitation at a concentration of about $5 \%$.

The starting materials were weighed according to the formula $\mathrm{Mn}_{0.7} \mathrm{Zn}_{0.2} \mathrm{Fe}_{2.1} \mathrm{O}_{4}$. Suitable $\left(\mathrm{NH}_{4}\right)_{2} \mathrm{C}_{2} \mathrm{O}_{4} \cdot \mathrm{H}_{2} \mathrm{O}$ and $\mathrm{NH}_{3} \cdot \mathrm{H}_{2} \mathrm{O}$ were initially added into $0.1 \mathrm{~mol} / \mathrm{L} \mathrm{FeCl}_{3} \cdot 6 \mathrm{H}_{2} \mathrm{O}$ solution under constant magnetic stirring to remain $\mathrm{pH}$ value of the solution at about 4 . Then $0.9 \mathrm{~mol} / \mathrm{L} \mathrm{MnSO}_{4} \cdot \mathrm{H}_{2} \mathrm{O}$ and $0.2 \mathrm{~mol} / \mathrm{L} \mathrm{ZnSO}_{4} \cdot 7 \mathrm{H}_{2} \mathrm{O}$ were introduced to the above solution. The $\left(\mathrm{NH}_{4}\right)_{2} \mathrm{C}_{2} \mathrm{O}_{4} \cdot \mathrm{H}_{2} \mathrm{O}$ and $\mathrm{NH}_{3} \cdot \mathrm{H}_{2} \mathrm{O}$ were re-added into the solution till its $\mathrm{pH}$ value of 8.5. At last, $\mathrm{NaOH}$ was added to the solution until its $\mathrm{pH}$ value of 13 . Then the solution was refluxed for $7 \mathrm{~h}$. The obtained precipitated product was washed with distilled water until a clear solution, and then dried at $80^{\circ} \mathrm{C}$ for $7 \mathrm{~h}$. The dried powder was calcinated between $400^{\circ} \mathrm{C}$ to $1200^{\circ} \mathrm{C}$ under different atmosphere.

\subsection{Sample Characterization}

X-ray diffraction (XRD) patterns were recorded at room temperature with a Bruker AXS X-ray diffractometer using a $\mathrm{Cu}-\mathrm{K} \alpha$ radiation at a continuous scanning rate of $10 \mathrm{~min}^{-1}$ in the $2 \theta$ range of $10^{\circ}$ to $90^{\circ}$. Crystallite size of the samples was calculated according to (311) peak in the XRD patterns using the Debye-Scherrer's equation:

$$
\mathrm{D}=0.94 \lambda / \beta \cos \theta
$$

where $\lambda$ is the X-ray wavelength, $\theta$ is Bragg's angle and $\beta$ is full width at half the maxima (FWHM). The saturation magnetization $M_{s}$, remanence magnetization, $M_{r}$, and coercive force, $H_{c}$, of the samples were calculated in terms of hysteresis loops measured by LakeShore-7400 vibrating sample magnetometer (VSM). In order to identify possible phase transformation in samples, the TG/DTA measurements were conducted in $\mathrm{N}_{2}$ between $25^{\circ} \mathrm{C}$ and $1200^{\circ} \mathrm{C}$ at a rate of $10^{\circ} \mathrm{C} \mathrm{min}{ }^{-1}$ using a Thermo Analyzer (TA, SDT-DTA 2960).

\section{Results and Discussion}

Figure 1 shows XRD patterns of as-synthesized samples, of which XRD peaks match well with those of the spinel MnZn ferrite (JCPDS No.74-2402). Almost no other peaks are found in the XRD patterns. Those results suggest that the samples prepared at different $\mathrm{pH}$ values are pure MnZn ferrite with spinel structure. In addition, apparent widening in the XRD peaks indicates a nano-scale crystallit size in those samples, and the narrower $\mathrm{XRD}$ peaks suggest that the crystals enlarge with an increase in the $\mathrm{pH}$ values (about $17 \mathrm{~nm}$ at $\mathrm{pH}$ of 12, and 25 $\mathrm{nm}$ at $\mathrm{pH}$ of 13).

Figure 2 shows the measured room-temperature hysteresis loops of the samples in Figure 1. Upon increasing $\mathrm{pH}$ values in the co-precipitation solutions, the saturation magnetization, $\mathrm{M}_{\mathrm{s}}$, apparently increase. And the 


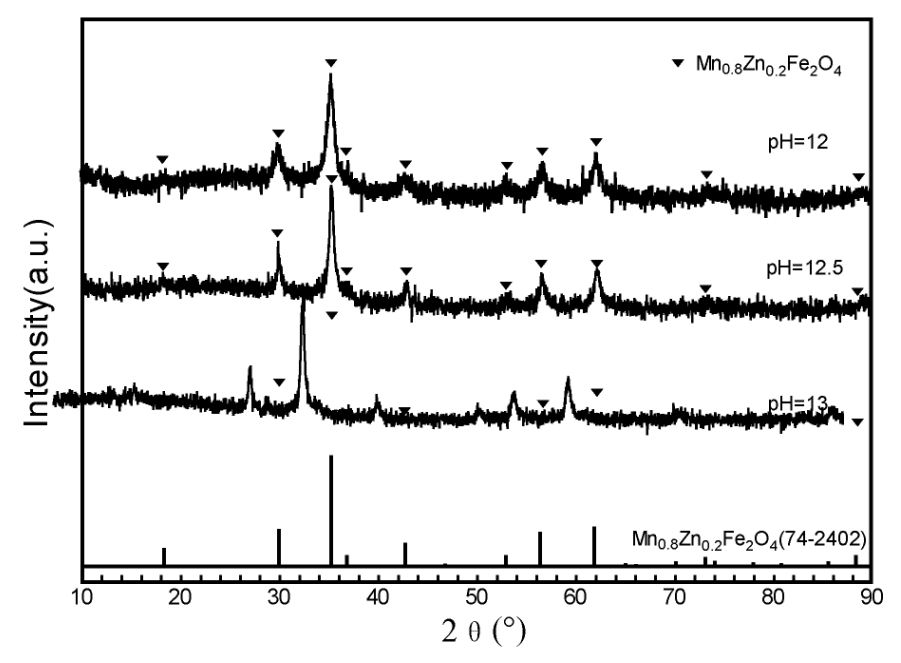

Figure 1. XRD patterns for the samples synthesized at various $\mathrm{pH}$ values.

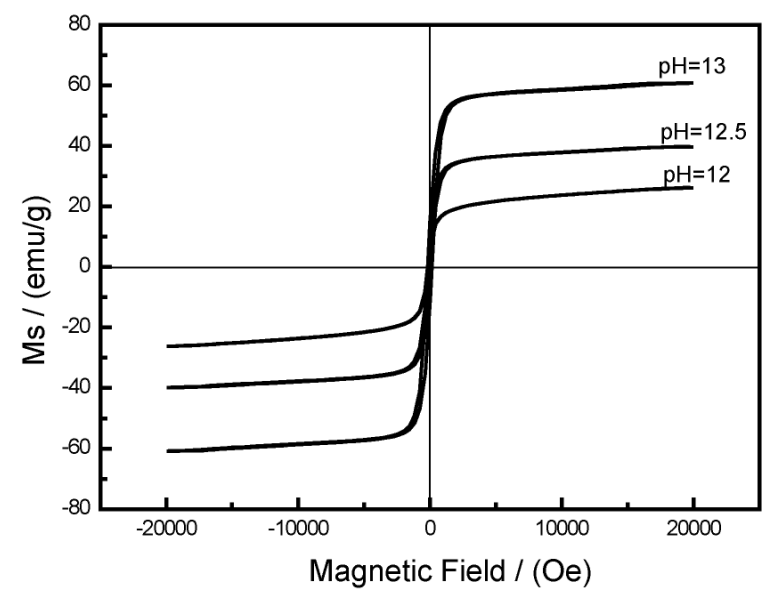

Figure 2. Magnetic hysteresis loops for the samples in Figure 1.

maximum $\mathrm{M}_{\mathrm{s}}$ of $58.6 \mathrm{emu} / \mathrm{g}$ is obtained in the sample at a $\mathrm{pH}$ of 13 . This $\mathrm{M}_{\mathrm{s}}$ value is almost the highest one reported recently [5] [19]-[22], is about one times larger than that of $\mathrm{pH}=12$. Similar results were reported by Narasimhan et al. [23].

It is known that magnetism of the powdered MnZn ferrite is tightly related to its crystal size. Szczygiel et al. [24] found that superparamagnetism occurred in the MnZn ferrite powder with its crystal size less than $10 \mathrm{~nm}$. Therefore, decrease in $\mathrm{M}_{\mathrm{s}}$ with decrease in $\mathrm{pH}$ value should be attributable to the decrease in the crystallite size of the samples in the present research.

It is reported that MnZn ferrite cannot be directly obtained by using oxalate as precipitant during the co-precipitation process, and that heat treatment at certain temperature is generally needed to precursor [16] [22]. Results obtained in the present research not only simplify the preparation process of the MnZn ferrite, but also improve its quality because inclusion is easily produced during the heat treatment.

Figure 3 shows thermal analysis curves of the sample prepared at $\mathrm{pH}$ of 13 . Total mass loss of the sample is about $8 \%$ during heating between room temperature and $1000^{\circ} \mathrm{C}$, and the sharp mass loss occurring below $400^{\circ} \mathrm{C}$ should be attributable to evaporation of the adsorbed water and the crystallized water contained in the sample. No apparent endothermal or exothermal peaks are found in the DTA curves. Those results further prove that the samples prepared in this research are pure MnZn ferrite.

The MnZn ferrite is generally used in the bulk state, and then a sintering process is needed for the powdered one. However, the MnZn ferrite is reported to easily decompose according to Equation (2) in a heated state 


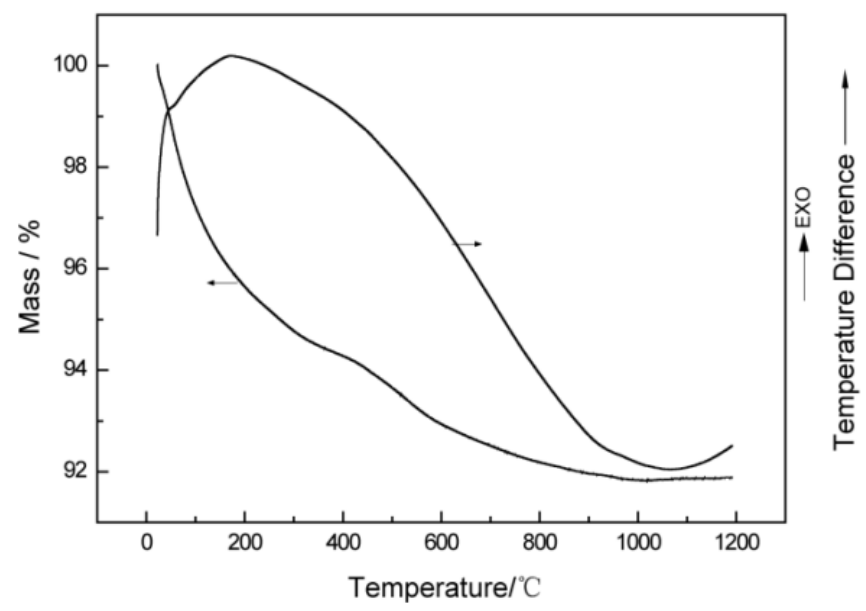

Figure 3. TG and DTA curves measured in $\mathrm{N}_{2}$ for the sample at $\mathrm{pH}$ of 13 .

under the oxidation atmosphere [2], and precipitation of $\mathrm{Fe}_{2} \mathrm{O}_{3}$ greatly deteriorates its magnetic properties.

$$
\mathrm{Mn}_{\mathrm{x}} \mathrm{Zn}_{1-\mathrm{x}} \mathrm{Fe}_{2} \mathrm{O}_{4}+\mathrm{x} / 4 \mathrm{O}_{2} \rightarrow(1-\mathrm{x}) \mathrm{ZnFe}_{2} \mathrm{O}_{4}+\mathrm{x} / 2 \mathrm{MnO}_{3}+\mathrm{XFe}_{2} \mathrm{O}_{3}
$$

Accordingly, we investigate phase transitions and variation in magnetic properties of the prepared samples during calcinations. Figure 4 shows XRD patterns of the calcinated samples under different atmosphere. XRD patterns of the uncalcinated ones are also presented in this figure for comparison. Under certain atmosphere, XRD peaks of the sample become stronger in intensity and narrower in width, followed by a gradual color variation form brown to dark brown, with an increase in the calcination temperature. It is noteworthy that some XRD peaks attributable to $\mathrm{Fe}_{2} \mathrm{O}_{3}$, concomitant with a reddish color in sample, appear in the XRD pattern of the sample calcinated at $800^{\circ} \mathrm{C}$ under $\mathrm{N}_{2}$ atmosphere. Further calcination at high temperature results in disappearance of those XRD peaks. Precipitation of some $\mathrm{Fe}_{2} \mathrm{O}_{3}$ from the $\mathrm{MnZn}$ ferrite may result from a little oxygen existing in the $\mathrm{N}_{2}$ atmosphere. In contrast, the $\mathrm{CO}_{2}+\mathrm{H}_{2}$ atmosphere is favorable to remain stability of the MnZn ferrite.

The measured hysteresis loops of the samples corresponding to those in Figure $\mathbf{4}$ are shown in Figure $\mathbf{5}$. Their magnetization nearly saturates at the maximum field of $20 \mathrm{kOe}$, the magnetic parameters like $\mathrm{M}_{\mathrm{s}}, \mathrm{M}_{\mathrm{r}}$ and $\mathrm{H}_{\mathrm{c}}$ calculated according to Figure 5 are presented in Table 1. Decrease in $\mathrm{M}_{\mathrm{s}}$ with an increase in the calcination temperature below $800^{\circ} \mathrm{C}$ under $\mathrm{N}_{2}$ atmosphere should be related to decomposition of the MnZn ferrite or precipitation of non-magnetic $\mathrm{Fe}_{2} \mathrm{O}_{3}$, shown in Figure 4(a). Solution of the $\mathrm{Fe}_{2} \mathrm{O}_{3}$ into the MnZn ferrites at $1000^{\circ} \mathrm{C}$ results in a sharp increase in $\mathrm{M}_{\mathrm{s}}$ from 27.1 to $80.3 \mathrm{emu} / \mathrm{g}$. On the other hand, the $\mathrm{M}_{\mathrm{s}}$ gradually increases with an increase in the calcination temperature below $1100^{\circ} \mathrm{C}$ for the samples calainated under $\mathrm{CO}_{2}+\mathrm{H}_{2}$ atmosphere, concomitant with a decrease in $\mathrm{H}_{\mathrm{c}}$. The highest $\mathrm{M}_{\mathrm{s}}$ of $188.2 \mathrm{emu} / \mathrm{g}$ is obtained for the sample, with the crystallite size of about $68.1 \mathrm{~nm}$, calcinated at $1000^{\circ} \mathrm{C}$. This is consistent with growth in crystallite size of samples during the calcination. The sharp decrease in $\mathrm{M}_{\mathrm{s}}$ at $1200^{\circ} \mathrm{C}$ is perhaps related to evaporation of some elements like $\mathrm{Zn}$ at high temperate. The $\mathrm{M}_{\mathrm{s}}$ of the samples under $\mathrm{CO}_{2}+\mathrm{H}_{2}$ is larger than that of $\mathrm{N}_{2}$ at same calcinations temperature.

\section{Conclusion}

MnZn ferrite nanoparticles could be directly prepared by using co-precipitation and then refluxing process. Crystallite size of the obtained samples increased with an increase in $\mathrm{pH}$ value of the co-precipitation solution, and that the crystallite size of about $25 \mathrm{~nm}$ was obtained for the sample at a $\mathrm{pH}$ of 13 . This sample also showed the maximum $\mathrm{M}_{\mathrm{s}}$ of $58.6 \mathrm{emu} / \mathrm{g}$, which was about one times larger than that of 12 ( $\mathrm{pH}$ value). Calcination to the obtained samples resulted in an enlargement in their crystal size and an improvement in magnetic properties with an increase in temperatures. The samples calcinated in $\mathrm{CO}_{2}+\mathrm{H}_{2}$ atmosphere presented good stability, and the maximum $\mathrm{M}_{\mathrm{s}}$ of $188.2 \mathrm{emu} / \mathrm{g}$ was obtained for the sample heated at $1100^{\circ} \mathrm{C}$. Unfortunately, precipitation of some $\mathrm{Fe}_{2} \mathrm{O}_{3}$ at $800^{\circ} \mathrm{C}$ suggested poor stability of the nanocrystalline MnZn ferrite in $\mathrm{N}_{2}$ atmosphere. 


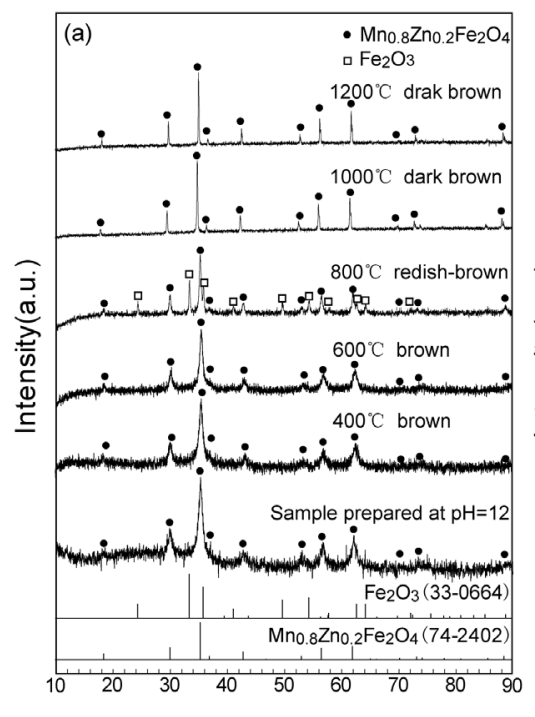

$2 \theta\left(^{\circ}\right)$

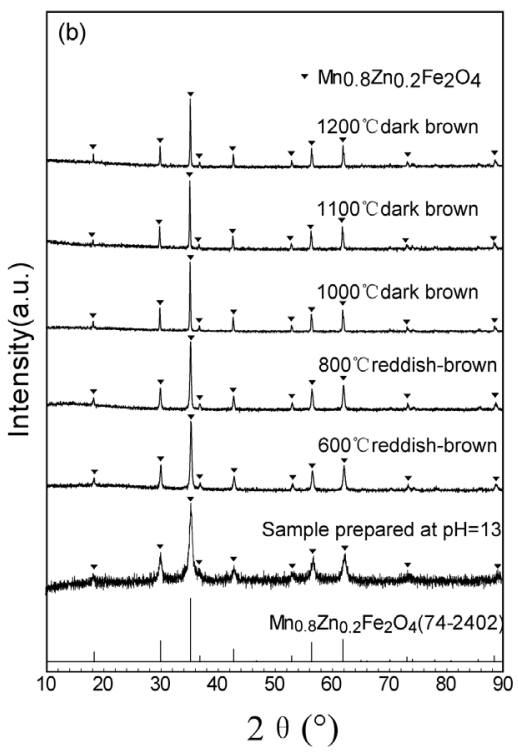

Figure 4. XRD patterns of the samples under different temperatures, (a) $\mathrm{N}_{2}$ and (b) $\mathrm{CO}_{2}+\mathrm{H}_{2}$.
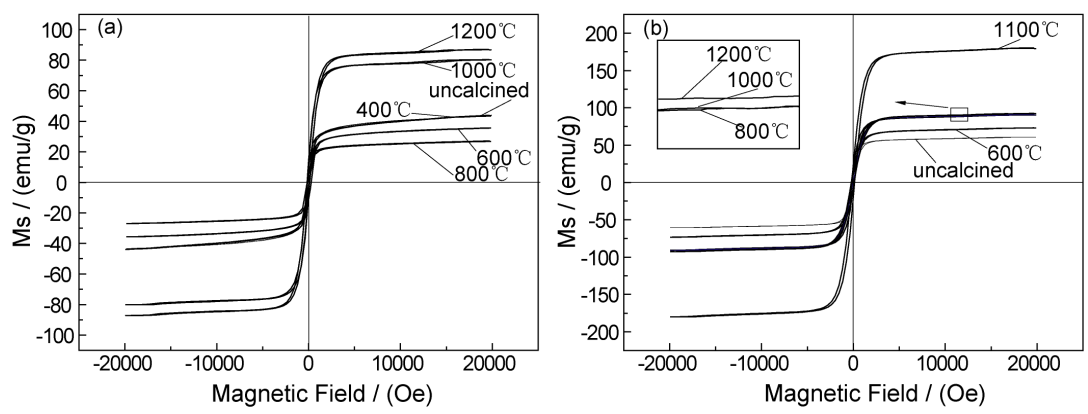

Figure 5. Hysteresis loops of the samples corresponding to those in Figure 4, (a) $\mathrm{N}_{2}$ and (b) $\mathrm{CO}_{2}+\mathrm{H}_{2}$.

Table 1. Magnetic properties of the samples calculated in terms of Figure 5.

\begin{tabular}{|c|c|c|c|c|c|}
\hline atmosphere & Calcined Temperature $\mathrm{T}\left({ }^{\circ} \mathrm{C}\right)$ & $\mathrm{M}_{\mathrm{s}}(\mathrm{emu} / \mathrm{g})$ & $\mathrm{H}_{\mathrm{c}}(\mathrm{Oe})$ & $\mathrm{M}_{\mathrm{r}}(\mathrm{emu} / \mathrm{g})$ & Crystallite size (nm) \\
\hline \multirow{5}{*}{$\mathrm{N}_{2}$} & 400 & 43.9 & 118.4 & 7.3 & 32.9 \\
\hline & 600 & 35.7 & 80.1 & 4.0 & 18.5 \\
\hline & 800 & 27.1 & 58.4 & 2.2 & 26.0 \\
\hline & 1000 & 80.3 & 135.1 & 11.4 & 52.8 \\
\hline & 1200 & 87.2 & 123.6 & 9.8 & 81.6 \\
\hline \multirow{5}{*}{$\mathrm{CO}_{2}+\mathrm{H}_{2}$} & 600 & 73.1 & 195.3 & 14.1 & 31.7 \\
\hline & 800 & 90.9 & 175.7 & 17.2 & 33.5 \\
\hline & 1000 & 90.8 & 128.1 & 9.0 & 63.4 \\
\hline & 1100 & 180.2 & 128.6 & 18.9 & 68.1 \\
\hline & 1200 & 92.6 & 126.1 & 9.0 & 69.3 \\
\hline
\end{tabular}

\section{Acknowledgements}

This work was supported by Tianjin Research Program of Application Foundation and Advanced Technology (major project) under a contract No.15JEZDJC31000. 


\section{References}

[1] Hu, P., Yang, H.B., Pan, D.A., Wang, H., Tian, J.J., Zhang, S.G., Wang, X.F. and Volinsky, A.A. (2010) Heat Treatment Effects on Microstructure and Magnetic Properties of Mn-Zn Ferrite Powders. J. Magn. Magn. Mater., 322, 173177. http://dx.doi.org/10.1016/j.jmmm.2009.09.002

[2] Waqas, H. and Qureshi, A.H. (2010) Low Temperature Sintering Study of Nanosized Mn-Zn Ferrites Synthesized by Sol-Gel Auto Combustion Process. J. Therm. Anal. Calorim., 100, 529-535. http://dx.doi.org/10.1007/s10973-009-0590-6

[3] Šepelak, V., Heitjans, P. and Becker, K.D. (2007) Nanoscale Spinel Ferrites Prepared by Mechanochemical Route. J. Therm. Anal. Calorim., 90, 93-97. http://dx.doi.org/10.1007/s10973-007-8481-1

[4] Sharifi, I., Shokrollahi, H. and Amiri, S. (2012) Ferrite-Based Magnetic Nanofluids Used in Hyperthermia Applications. J. Magn. Magn.Mater., 324, 903-915. http://dx.doi.org/10.1016/j.jmmm.2011.10.017

[5] Zhang, C.F., Zhong, X.C., Yu, H.Y., Liu, Z.W. and Zeng, D.C. (2009) Effects of Cobalt Doping on the Microstructure and Magnetic Properties of Mn-Zn Ferrites Prepared by the Co-Precipitation Method. Physica B: Condensed Matter, 404, 2327-2331. http://dx.doi.org/10.1016/j.physb.2008.12.044

[6] Isfahani, M.J.N., Myndyk, M., Menzel, D., Feldhoff, A., Amighian, J. and Šepelak, V. (2009) Magnetic Properties of Nanostructured MnZn Ferrite. J. Magn. Magn. Mater., 321,152-156. http://dx.doi.org/10.1016/j.jmmm.2008.08.054

[7] Kadu, A.V., Jagtap, S.V. and Chaudhari, G.N. (2009) Studies on the Preparation and Ethanol Gas Sensing Properties of Spinel $\mathrm{Zn}_{0.6} \mathrm{Mn}_{0.4} \mathrm{Fe}_{2} \mathrm{O}_{4}$ Nanomaterials. Curr. Appl. Phys., 9, 1246-1251. http://dx.doi.org/10.1016/j.cap.2009.02.001

[8] Jeyadevan, B., Tohji, K., Nakatsuka, K. and Narayanasamy, A. (2000) Irregular Distribution of Metal Ions in Ferrites Prepared by Co-Precipitation Technique Structure Analysis of Mn-Zn Ferrite Using Extended X-Ray Absorption Fine Structure. J. Magn. Magn. Mater., 217, 99-105. http://dx.doi.org/10.1016/S0304-8853(00)00108-6

[9] Venkataraju, C., Sathishkumar, G. And Sivakumar, K. (2010) Effect of Nickel on the Electrical Properties of Nanostructured MnZn Ferrite. J. Alloys Compd., 498, 203-206. http://dx.doi.org/10.1016/j.jallcom.2010.03.160

[10] Iqbal, M.A., Islam, M.U., Ali, I., Kan, H.M., Mustafa, G. and Ali, I. (2013) Study of Electrical Transport Properties of $\mathrm{Eu}^{+3}$ Substituted MnZn-Ferrites Synthesized by Co-Precipitation Technique. Ceram. Int., 39, 1539-1545. http://dx.doi.org/10.1016/j.ceramint.2012.07.104

[11] Fan, J.W. and Sale, F.R. (1996) Analysis of Power Loss on Mn-Zn Ferrites Prepared by Different Processing Routes. IEEE Trans. Magn., 32, 4854-4856. http://dx.doi.org/10.1109/20.539174

[12] Azadmanjiri, J. (2007) Preparation of Mn-Zn Ferrite Nanoparticles from Chemical Sol-Gel Combustion Method and the Magnetic Properties after Sintering. J. Non-Cryst. Solids, 353, 4170-4173. http://dx.doi.org/10.1016/j.jnoncrysol.2007.06.046

[13] Rozman, M. and Drofenik, M. (1995) Hydrothermal Synthesis of Manganese Zinc Ferrites. J. Am. Ceram. Soc., 78, 2449-2455. http://dx.doi.org/10.1111/j.1151-2916.1995.tb08684.x

[14] Yener, D.O. (1988) Synthesis of Pure and Manganese-, Nickel-, and Zinc-Doped Ferrite Particles in Water-in-Oil Microemulsions. J. Am. Ceram. Soc., 84, 1987-1995. http://dx.doi.org/10.1111/j.1151-2916.2001.tb00947.x

[15] Mathew, D.S. and Juang, R.S. (2007) An Overview of the Structure and Magnetism of Spinel Ferrite Nanoparticles and Their Synthesis in Microemulsions. Chem. Eng. J., 129, 51-65. http://dx.doi.org/10.1016/j.cej.2006.11.001

[16] Angermann, A. and Töpfer, J. (2011) Synthesis of Nanocrystalline Mn-Zn Ferrite Powders through Thermolysis of Mixed Oxalates. Ceram. Int., 37, 995-1002. http://dx.doi.org/10.1016/j.ceramint.2010.11.019

[17] Ghodake, S.A., Ghodake, U.R., Sawant, S.R., Suryavanshi, S.S. and Bakare, P.P. (2006) Magnetic Properties of NiCuZn Ferrites Synthesized by Oxalate Precursor Method. J. Magn. Magn. Mater., 305, 110-119. http://dx.doi.org/10.1016/j.jmmm.2005.11.041

[18] Fritsch, S.G., Viguié, S. and Rousser, A. (1999) Structure of Highly Divided Nonstoichiometric Iron Manganese Oxide Powders $\mathrm{Fe}_{3-\mathrm{x}} \mathrm{Mn}_{\mathrm{x} \square 3 \delta / 4} \mathrm{O}_{4+\delta}$. J. Solid State Chem., 146, 245-252. http://dx.doi.org/10.1006/jssc.1999.8345

[19] Cao, X., Liu, G., Wang, Y., Li, J.H. and Hong, R. (2010) Preparation of Octahedral Shaped $\mathrm{Mn}_{0.8} \mathrm{Zn}_{0.2} \mathrm{Fe}_{2} \mathrm{O}_{4} \mathrm{Ferrites}$ via Co-Precipitation. J. Alloys Compd., 497, L9-L12. http://dx.doi.org/10.1016/j.jallcom.2010.03.011

[20] Arulmurugana, R., Vaidyanathana, G., Sendhilnathanb, S. And Jeyadevan, B. (2006) Mn-Zn Ferrite Nanoparticles for Ferrofluid Preparation: Study on Thermal-Magnetic Properties. J Magn Magn Mater, 298, 83-94. http://dx.doi.org/10.1016/j.jmmm.2005.03.002

[21] Meng, Y.Y., Liu, Z.W., Dai, H.C., Yu, H.Y., Zeng, D.C., Shukla, S. and Ramanujan, R.V. (2012) Structure and Magnetic Properties of $\mathrm{Mn}(\mathrm{Zn}) \mathrm{Fe}_{2-\mathrm{x}} \mathrm{RE}_{\mathrm{x}} \mathrm{O}_{4}$ Ferrite Nano-Powders Synthesized by Co-Precipitation and Refluxing Method. Powder Technol., 229, 270-275. http://dx.doi.org/10.1016/j.powtec.2012.06.050

[22] Angermann, A., Töpfer, J., Silva, K.L. and Becker, K.D. (2010) Nanocrystalline Mn-Zn Ferrites from Mixed Oxalates: 
Synthesis, Stability and Magnetic Properties. J. Alloys Compd., 508, 433-439. http://dx.doi.org/10.1016/j.jallcom.2010.08.083

[23] Narasimhan, B.R.V., Prabhakar, S., Manohar, P. and Gnanam, F.D. (2002) Synthesis of Gamma Ferric Oxide by Direct Thermal Decomposition of Ferrous Carbonate. Mater. Lett., 52, 295-300. http://dx.doi.org/10.1016/S0167-577X(01)00409-8

[24] Szczygiel, I., Winiarska, K., Bieńko, A., Suracka, K. and Koniarek, G.D. (2014) The Effect of the Sol-Gel Autocombustion Synthesis Conditions on the Mn-Zn Ferrite Magnetic Properties. J. Alloys Compd., 604, 1-7. http://dx.doi.org/10.1016/j.jallcom.2014.03.109 